\title{
Movies, Memories and Merriment Making Postmodern Spaces in Los Angeles
}

\author{
Greg Dickinson \\ La Sierra University, $C A$
}

\begin{abstract}
"For some populations at some times, commercialized leisure is history-a repository of collective memory that places immediate experience in the context of change over time." (Lipsitz 5)

"The insistent message of a postmodern Los Angeles is that all previous urban place-making bets are off; we are engaged, knowingly or otherwise, in the search for new ways of creating cities. There is reason to believe that if success is not possible in the prototypical metropolis of Southern California, then it may well be impossible in any city in the United States." (Dear 74-75)
\end{abstract}

If we want to talk about postmodernity, we must, it seems, talk about space (Gibson \& Watson). More specifically, we need to talk about cities. Postmodernity, as a cultural phenomenon is many things, but it is at least partly constituted as an urban phenomenon. Where cities like New York and Chicago, and in Europe Paris and London may represent modernity, the Western US cities like Phoenix, Dallas-Fort Worth, San Antonio, Seattle, Portland and Denver and a range of cities in the Central and South America and across Asia are the sites of postmodernity. But perhaps the most important location of postmodernity, in the US at least, is metropolitan Los Angeles (Scott; Soja) ${ }^{1}$ It is within sites like metropoli$\tan$ Los Angeles that the forces of postmodernity are most clearly "located," or perhaps better, "placed."

But of course, I must be careful with such loaded words as "located" and "placed" in reference to postmodernity. For postmodernity seems to be a time of dis-location, displacement, and, for many dis-(re)pair. But it is this very sense of dis-placement fostered by postmodernity in general and the postmodern city in particular that must be investigated through careful analysis of particular sites, for postmodernity, though perhaps a general phenomena, is enacted in local sites. The almost overwhelming sense of dislocation within the contemporary era calls forth, among other responses, memory. Memory, and in particular as I will argue below, landscapes of memory, strive to create secure "place" where individuals can regain a stable sense of identity. Thus, at the very moment when we seem to be most fragmented, most estranged from connection and control, landscapes of memory are offered to unify the self through stabilized connections to the past. More than offering memories to stabilize the self, they also assert their ability to provide appropriate space for

\footnotetext{
${ }^{1}$ Metropolitan Los Angeles covers, by most reckonings, four counties-Los Angeles, Orange, Riverside, and San Bernardino. This covers not only an immense physical territory (stretching from the Pacific ocean to Arizon and Nevada on the east), but includes one of the largest population centers in the world. The largest economic center and, arguably, the most important center for the production of cultural as well as material goods.
} 
civic interaction between subjects. In this essay I will explore the ways postmodernity challenges the civility of cities, and the ways in which one postmodern space in Los Angeles-Universal CityWalk-responds to this challenge.

Many critics of postmodernity and of postmodern cities and spaces in particular argue that the city appears to have disappeared. Susan Buck-Morss argues that the "real" city has been replaced by the image of the city. She writes: "As actual cities disintegrate, the image of the city gains in market appeal. Like an echo of the call for social utopia, the mirage of the existence of collective desire, the city-image enters the domestic landscape." Power, she asserts, resides elsewhere, it is no longer found in cities but along_transnational networks of electronic communication and commerce. What is more, postmodern architecture, while it replays the memory of the dreams for social power and social utopia, always reminds allknowing and increasingly cynical adults that these dreams are impossible, elided by the networks of consumption. Buck-Morss of course, is not alone in this assessment of contemporary urban spaces and urban building. The fragmentation of contemporary culture carried out through consumerism, transnational politics and corporations, the spread of high-speed information and transportation technologies, work to unmake both the subject and the city. Indeed, there is more than a coincidental connection here. Diane Agrest, putting this problem squarely in the public space asserts that "we are dealing with the modern city. ... There is no subject here," she asserts (190).

The anger and the passion with which many critics write about the putative loss of public space can be read as a way of understanding the loss of the individual as a unified and as a political subject. In fact this is Buck-Morss' very concern, for real adults, she asserts, have lost faith in the dream of social utopia. Of course utopia is the place where problems are solved and unity is finally achieved. This unity is often based on the notion of a subject who can, ideally at least, understand itself and, at the same time, communicate that understanding in transparent ways to a listener. But indeed, we have lost our sense that that is possible. Writing out of a deeply liberal tradition, Robert Bellah and his colleagues write in Habits of the Heart that "the American search for spontaneous community with the likeminded is made urgent by the fear that there may be no way at all to relate to those who are different. Thus the tremendous nostalgia many Americans have for the idealized "small town." It is this fear, this melancholic loss of personal, communal, national and spatial identities that motivates the interest in and desire for comforting mnemonic images of cities.

Images of cities, then, do more than simply recall for the citizen a time when cities actually worked, they also serve the function of "replacing" lost unity, unity of subjectivity or the unity of the self. This desired return to unity, then, is at least one motivation for the constant clamour over building urban sites heavily influenced by mass mediated images. Since it seems to be the barrage of image excess that has unmade unity, city spaces constructed out of yet more images are precisely the spaces that most concern critics desiring the possibility of unified moral and political grounding. 


\section{(In LA) The façade is real}

Universal CityWalk seems to fit precisely into this problem. It is at once an attempt to build a "universal" CityWalk, but as Buck-Morse points out, real adults have given up on the possibility of utopia and thus of universality. At the same time CityWalk is a mnemonic theme park to/for/of Los Angeles. The site is filled with icons and images of LA, from surfboards to cars, highway signs to beaches, from Rem Koolhaus to Frank Ghery, from neon to movies. The landscapes referenced and the icons used are those crucial to the way LA presents itself through media to itself and the outside world. Thomas King, writing in the Wall Street Journal, describes CityWalk's landscape as made up of a "faux Venice Beach, the billboards and neon of Sunset Boulevard, the neo-Mexican facades of Olvera Street and the chic shops of Melrose Avenue" (B1). Clearly, the landscapes referenced are archetypal LA places. Venice beach stands in for all the beaches of Los Angeles, Melrose for trendiness, Olvera for the city's Mexican heritage. CityWalk is clearly referencing real places, and, more importantly, the place in which it resides, Los Angeles. At the same time, the beach is fake and the façades are mere copies.

(Un)fortunately, the Los Angeles memorialized never existed, at least not outside of media images of itself. CityWalk, it would appear, is nothing more than a façade, an ersatz street memorializing ersatz and nostalgic images of a city that itself seems built on images. CityWalk, in its explicit referencing to both movie images and images of the city is a crucial site in new negotiations of urbanity and urban living within the excesses of the information age. Indeed, if Los Angeles itself is built on images as many argue to be the case, if understanding of Los Angeles is always, already filtered through the massive array of images, then memorializing and calling forth these memories may not be so false after all. It may be that the façade is real.

\section{Real Cities Are Not So Much Fun}

This raises the question, in what way might Universal CityWalk be a real city walk, that is a real civic space? In fact, many argue that it is not a real civic space, rather it is an entertaining fake, a fake that has the power to overcome real and difficult public spaces. The fact, of course, that both the building and the street are owned by a transnational entertainment conglomerate makes this case compelling. As in a mall, the privacy of the property makes it easier to regulate behavior and speech. In fact, CityWalk has a specific dress code that would be much more difficult to create and enforce in real public spaces. In September of 1994, CityWalk banned cussing and wearing baseball caps backwards in hopes of dispelling a growing fear that gangs had discovered the walk (Schanufer B4). Part of the purpose of these rules was to discourage gang members from coming to CityWalk. Just as important, though, was the elimination of gang style. This kind of dress code, while often desired in public spaces is difficult to create and often seen as unconstitutional.

Eliminating gangs (more importantly the racial and class tensions they embody) and the fear they bring is crucial to CityWalk's success. The dress code is only one part of a multi- 
pronged effort to make CityWalk a "safe" place to visit. A second important set of decisions surrounds the movies shown at the adjacent theaters. In 1993, for example, Menace II Society and Posse, both black films, were passed over by the theater. CityWalk executives were determined to not repeat the violence that erupted just a year before in Westwood. Careful selection of movies not only discourages attendance of some audience members but can also encourage attendance of others. Clearly, CityWalk's unreality, it spatial and historic disconnection from LA and its problems and its status as private space makes it impossible for CityWalk to fill the role of public space as traditionally defined.

At the same time, for many in America, making choices within the consumer landscape, in particular asserting personal and group identity through decorum and lifestyle choices is a significant way of staking a claim in public discussions. Public life is increasingly inflected by and lived through consumer culture and practices. As George Lipsitz argues, for some in America and for some of the time, mass mediated popular culture provides the historic grounding needed to make critical claims about past present and future In making clothing choices, restaurant choices, movie and music choices, individuals buy into and enact identities that are at once individual and social, personal and political. The consistent discussions, for example, over movie, music and television content; the willingness of groups to boycott or advocate particular films, studios or firms based on the entertainment productions; and the discussions over which films to book and what clothing and personal practices to ban or encourage all suggest that interactions in spaces like Universal CityWalk are part of larger discussions over power, persons and voices.

The use of new and old, the regeneration of older and contemporary Los Angeles forms, the attempts to work out relations among film, television, radio, food, clothing and other consumables and the vast diversity of visual styles, all potentially serve as structures and resources that might be helpful in understanding Los Angeles and contemporary life. Questions of political practice, religious belief, technological innovation, the explosion of mass mediated consumer culture and the individual's position within this culture area all at play. Through out the space these issues remain to the fore: the huge Fender Guitar fronting the Hard Rock Cafe suggests the overwhelming force of media culture and the difficulty of resisting its force. Star Takes, a store that puts customers' images into films urges visitors to play out their fantasy of being a star, if only for a moment. At the same time, The Nature Company resists the emphasis on surface presentations and falsity of the urban setting by reinforcing the importance of the natural world, while at the same time turning the "natural world" into a commodity. B.B. King's Blues Club draws people away from the slick presentations into a world of seeming authentic American music that struggles with good and evil and the oppressions fundamental to the American experience.

CityWalk is, within the world of media access and excess, the real thing. A rhetorical and physical locus of the cultural structures and possibilities, a place devoted to the enactment of media constrained and created identities, a place of nearly overwhelming diversity and amazingly monotonous homogeneity, it is a place where you are free to express your mediated self, but only within the safety of corporately sanctioned structures. You can be a movie star wannabe, but you can't be a gang wannabe. You can tag your body, but you 
can't graffiti the walls. You can look like (and be) a corporate raider, but you'd best not look like a drug dealer. And you can dye your hair any color you want, but your baseball cap must be worn bill forward. A walk in CityWalk is a walk into the heart of the possibilities and tragedies of the late American city, where theme parks are safe alternatives to civic parks, CityWalks are preferable to urban walks and education is devoted to good consuming and the production of diverting and (not so) memorable mass media texts.

Does this make CityWalk bad? Is it a space to excoriate? Or is it an urban utopia, a first glance at a reasonable response to the profound difficulties facing cities today? It is both and neither. Clearly not utopian, especially for those unwelcome in its space, it is also not the worst possible scene. It is in fact, safe. It does draw a profoundly diverse crowd, it is neither public nor private, but some third space, the space occupied by landscapes of memory, landscapes of consumption and persons performing themselves and their culture. CityWalk may not be an Italian Piazza. But at the same time, the Italian Piazza, as powerful as it was, can only function in 1999 as a nostalgic image of time that might have been simpler, a time when citizenship counted. What kind of space should we be building now? And what kind of space can we build that is not already embedded in our visual culture? What kind of public space can we imagine for our performing, enacting and fragmenting selves?

\section{WORKS CITED}

Agrest, Diane. Architecture from Without: Theoretical Fragments for Architectural Practice. Cambridge: MIT Press, 1991.

Bellah, Robert, et al. Habits of the Heart. Individualism and Commitment in American Life. Berkeley: U of California P, 1985.

Dear, Michael. "Beyond the Post-Fordist City." Contention 5 (1995).

Gibson, Katherine, and Sophie Watson. "Postmodern Spaces, Cities, and Politics: An Introduction." Postmodern Cities and Spaces. Eds. Sophie Watson and Katherine Gibson. Oxford: Blackwell, 1995.

King, Thomas R. "Mall Replicates a Sanitized Los Angeles." Wall Street Journal, 10 May 1993.

Lipsitz, George. Time Passages: Collective Memory and American Popular Culture. Minneapolis: U of Minnesota P, 1990.

Schnaufer, Jerry. "CityWalk Tightening Security in Wake of Melee." Los Angeles Times, 7 August 1994.

Scott, Allen. Technopolis: High-Technology Industry and Regional Development in Southern California. Berkley: U of California P, 1993.

Soja, Edward W. Postmodern Geographies. The Reassertion of Space in Critical Social Theory. London: Verso, 1989. 
